\title{
Some Necessary Translation Methods during the Transference of a Meaningful Message from One Cultural Identity to Another
}

\author{
Holta Heba \\ PhD candidate \\ The European University of Tirana Albania \\ holta.heba@uet.edu.al
}

\section{Doi:10.5901/jesr.2014.v4n3p119}

\begin{abstract}
The standards of identity, culture, tradition, and history cannot be misunderstood by another identity if there is a real linguistic and extra-linguistic translation. The communication point between interlocutors who do not come from the same country and do not share the same culture, who do not have the same origin and consequently do not share the same customs, is in need for a translator. The object of this research paper is: The cultural transference like the linguistic transfer is an absolute requirement in the communication between two different identities. The meaning is not merely a sum of words, but an organic meaningful unity that is expressed in non-identical ways in different identities. The research questions in this paper are: Is it possible to make a point of communication between two different cultures? What are the methods that make this communication possible in order to make the transference of meaningful messages possible?
\end{abstract}

Keywords: communication, cultural transformation, different identities, translation methods, meaningful message.

\section{Introduction}

Cultural transfer can not have a single and general solution. To illustrate how we resolved the cultural transference we can present a list of translation ways which are used when one wants to move from one culture to another.

The language itself can not be seen simply as a constant means of communication. It takes different forms and meanings based on the reality that it seeks to express under certain conditions.

Language is a two-way process: from the world to the word and from the word to the world. (Lloshi , $200: 346)$.

Cultural transformation is linked with the transformation of language. It can be compared to a gift-wrap that changes its shape in order to adapt to the gift it wraps to make it look nicer. A language that is not used correctly can not convey something in a meaningful way.

Language refers to culture. It helps transfer the culture from one part of the world to another. It varies from one individual to another, from one period to another and from one culture to another.

When we talk about two different cultures, the hand of a qualified translator is a very essential tool in the process of linguistic and cultural transference. Culture is a phenomenon that is closely related to identity. The latter one is more related to politics, history, religion and many traditions. The identity tells us who we are and where we came from. For example, religion is an identity element, which may not be the same in all countries. In addition, the story of a particular nation is an indicator of a certain identity that can never be the same.

\section{Cultural Transformation is Essential in the Transmission of Meaningful Message between Two Different Cultures}

The main problem with communication is to correctly transmit a meaningful message. A word, a phrase or a sentence would not make sense if they were not structured according to the internal system of the language and would not be semantically correct.

Translation means that one must understand the internal system of the language and the structure of a particular text in that particular language and then build a dual textual system"(Eco 2006: 17).

The dual textual system created by the interpreter should have similar consequences to the target language 
recipient at semantic, syntactic and stylistic level.

The source language message must be unchangeable when it comes to the target language.

What's more remarkable when comparing the texts is that during their translation both Cajupi and Kokona used a free artistic interpretation. They make their own interpretation of the meaning of the original text and they allow some fancy manipulations.

Like all translators who seek to maintain the sense of a message, both Cajupi and Kokona seem more interested in the public's perception than the fidelity to the original text. During the translation of a fable, personal interpretation is not prohibited, as it can happen with holy books. It is important to respect what the author meant in the original language and the parameters of the target language. The language used in the fable is a poetic language.

To understand the poetic language, four aspects must be assessed: the metrical form and rhythm, figures of speech, syntactic structures and morphosyntaxtic links. (Varfi , 1999: 156).

According to the interpretive theory of meaning we see the transmission of the message from French to Albanian that occurs during translation.

The interpreter is aware that in order to find the meaning of the words he must find the appropriate equivalence correspondence, so that the message of the source language corresponds to the message in the target language.

In the analysis of the research we will demonstrate the linguistic and cultural transformations when shifting from one culture to another and from one language to another. The analysis is performed to monitor the impact of these transformations, which are directly related to the meaning of the message.

\section{Some Methods used for Cultural Transference}

\subsection{Adaptation}

This is just an equivalent of the situation. This is when the interpreter must adapt the word found in the target language with the one in the source language.

In the process of translation it may happen that the translator is obliged to increase or decrease the amount of words in a sentence to clearly express the true concept. Some languages are more flexible, but some are not that flexible.

The translator's task is to adapt all linguistic and cultural elements, so that the message is semantically assimilated by the individuals in the target language.

\subsection{Conversion:}

When the source language concept does not exist in the target language, the translator must make it understandable to the public by providing the concept in the target language. This process occurs more often in the translation of proverbs and idioms.

Numerous examples of this approach will be presented during the critical analysis of fables. One social phenomenon can not be expressed in the very same way. For the interpreter, loyalty to the meaning remains indispensable, consequently the transformation in conformity with the cultural colours of the national identity remains one of the most practiced methods, especially in the genre of fables.

\subsection{The Explanation}

Words are used to identify individuals and different categories. When we talk about people, it is obvious that they retain their natural shape when switching from one language to another or from one culture to another.

When we talk about classes, word processing during translation requires an explanation by the translator. But based on the flexibility and restriction of a language one should not overlook the fact that when the translator is faced with concept that is incomprehensible for the reader of the target language, he is obliged to provide to give explanations until the message becomes understandable. 


\subsection{The ethnocentrism}

This is when the interpreter must change the facts according to his culture, to make it accessible to the recipient. In translation, this process is called "naturalization". Minimizing the differences from the original culture to his own culture, the translator makes it possible for a text that could remain elusive, to become very clear to the reader. All humanity shares certain universal habits like: eating, sleeping, etc.

In fact, these universal practices are not the culture itself. Culture is more related to how we are used to perform actions. These techniques vary from one identity to another. This is where the invisible hand of the artist, who tries to naturalize the phenomena, traditions and customs, performs in the target language. Each country has its cultural identity model.

Cultural transfer is a key point when talking about two different countries with different cultures and customs. Thanks to the cultural transference the foreign reader can recognize something that does not belong to his culture. To achieve this goal, the interpreter retains the foreign culture reference and transmits it in a comprehensible form to his culture culture, because this is the only way one can get to know a foreign culture.

The transition from one culture to another is a difficult process because the culture of a country is different from the culture of another country.

The same phenomenon is described in different forms in different countries. The implementation of this process requires commitment and perfect translation. The translation is the means by which the foreign word is stripped off the parameters of the source language and is dressed with the parameters of the target one. The translator's task is to know the source language culture as well as his own culture. Knowing a foreign culture one must understand and be able to transmit it to your culture in a clear way.

The methods mentioned above are some of the ones that make the cultural transference possible, but it should be noted that they are very necessary for the implementation of this process.

Lexical -semantic transformation in translation is done for a very important reason, since it is clear that in different cultures one signified does not have the same signifier.

As an inseparable link between the word and its contextual meaning, the linguistic expression loses its neutral nature and takes specific characteristics of each nation, social group, or particular political class. (Fuga. 2008: 210)

Each concept in French takes a contextual meaning in Albanian in conformity with the specific features of the Albanian language and culture.

\section{Some Examples of Methods Used in Cultural Transformations}

\subsection{Adaptation}

An example of what is stated above is the adaptation of impersonal nouns.

The Mice Assembly (page 37) is a fable in which the title has undergone a lexical transformation during translation.

La Fontaine fable begins with a gib called " Rodilardus ". Kokona does not translate this name and gives the gib the epithet "nefarious" " zullumqar " (verse 1, page 37).

This is an orientalism that does not appear in the version of La Fontaine, but the interpreter used an equivalent with the help of a name via a name that does not exist in the original text.

In fact, for an Albanian it is difficult to understand that " rodilardus " means a mischievous cat, and very problematic for the life of the mouse. In French the name is derived from the amalgamation of the words "Rong- lard" . (Classical Cambridge, 1957104 ).

In the language of La Fontaine " rodilardus " is a proper name, but in Albanian language, the name is transformed into an epithet that makes sense and helps the reader understand the story . In some respects, the adaptation of the proper name brings the story closer to the Albanian language.

When we look at Cajupi's translation, we understand that he also tries to remain very loyal to Albanian by choosing not to use the proper name Rodilardus. Indeed, in order to preserve the rhyme, Cajupi called cat named rodilardus as " a lonely cat. " " Një machok i shkretë / kish dërguar ndë atë jetë " (verse 1/2, page 43).

In this verse translated by Cajupi we can feel little instability concerning the meaning. A negative cat in the original language cannot be poor in the target language. A type of contradiction is felt in translation since a cat that has killed lots of mice cannot be considered as poor. 

the fable.

However, it is clear that Cajupi risked with the meaning of the message with the purpose of retaining the rhyme in

\subsection{Conversion}

"As soon as Phoebus rejected Tethys with golden hair" verse 6, page 74) is an idiom associated with mythological figures and La Fontaine used to show dawn. The word for word translation is: "Since Fabius rejects Tethys with golden hair". The interpreter translates this verse using the lexical transformation and transforms the entire verse: "Before the flame burning sun lit up the sky."

In both languages, it is understandable that reference is made to the "dawn." The only difference is the different way of expressing the "dawn". Comparing the two verses we see that the verse in Albanian lacks the mythological figures, but the meaning is the same.

\subsection{Explanation}

On page 111 is the fable " The Heron " in French and " Gata " in Albanian. In this fable we see the addition of the word " lady " four times before the word " heron ". The Interpreter wants to highlight the fact that the heron is very presumptuous. For this reason he always called " Mrs. Heron " in the Albanian version .

The same is also seen in the fable " The chariot and the fly " (page 119) where the a presumptuous fly claims that the horses move only if she whispers into their ears.

The word " lady " is added before the characters of fables to show that their actions are punishable, and the abovementioned word fits to these real presumptuous creatures that eventually perform wrongdoings and suffer the consequences of being presumptuous.

Thus, word addition in many fables is done for the sole reason of explaining the characteristic of being presumptuous by the translator. All these elements are used by the translator to transmit a coherent and clear to the reader. It is obvious that we can see a free choice that allows the author to convey the meaning of the fable. The addition of the word helps to keep the rhyme as well as the meaning .

\subsection{Ethnocentrism}

In the fable "The loop, the cat and the rabbit " in verses (23, 24 Page 136), the author lists a number of French names, which could be the owners of the rabbit house:

\footnotetext{
" To John, son or nephew of Peter or William,

Rather than Paul , rather than me."
}

All these names are translated through the demonstrative pronouns this or that. Proper names do not have the same meaning in the Albanian culture. We cannot imagine an Albanian to be named Jean Pierre or Paul .

For a more precise understanding of the fable it is necessary that the names to be replaced by names that are familiar to the Albanian culture.

In French fables these names are quite suitable, but in Albanian language in which the land patent is called "tapi" and the landlord is called " kadimyftiu " ( Orientalism ), we can no longer call a person by John, Pier, Guliem or Pol. These are actual French names. In this case, the appropriate names for Albanian fables would be: Gjoni , Guri , Gëzimi e Pali . These names can also be replaced by $x, y$ and $z$.

The order of the proper names is not important, but their choice is important. The translator has managed to avoid inconsistencies through ethnocentrism, by transforming the lexical framework in order to bring meaningful verses in Albanian language and replacing French names with typical Albanian demonstrative pronouns.

\section{Conclusion}

Communication between two languages and two cultures cannot be a literal translation because the meaningful message transfer can be altered. The language code is sacrificed in order to achieve a meaningful message. The meaning is not simply a bunch of words, but an organic meaningful unity.

Linguistic and extra-linguistic differences are still present as countries do not use the same language and the 
same culture.

Although the linguistic and cultural differences between France and Albania are numerous, as it was confirmed by the analysis above, we can say that these countries are not so distant perhaps as a result of many past and present exchanges between the two countries. We need to bear in mind that they belong to the same continent.

Challenges in translation appear in linguistic terms because languages use different codes of linguistic materials, but they are also of a cultural character as a result of non-compliance of customs, traditions, history and culture between France and Albania.

The abovementioned cultural transference methods become an essential tool in the communication between two different identities.

Their sole purpose is the transmission of meaningful messages in the process of cultural exchange between two or more identities that differ in history, culture, tradition and customs.

\section{Bibliography}

Çajupi, A. (1920). Përralla të zgjedhura nga të vjerështarit math, La fontaine, Heliopolis

Kokona, V. (2005). La Fonten, Fabula të zgjedhura. Tiranë: Botimet Kokona.

Dictionnaire Petit Robert. Robert, P. (1970). Paris: Societé du nouveau Littré

Dictionnaire du français primordial Micro Robert, Robert, P. (1977). Paris: Societé du nouveau Littré

Fjalor Frazeologjik Frengjisht-Shqip, Shijaku, E. (1998). Tiranë; Dituria

Lloshi, Xh, (2005) Stilistika e gjuhës shqipe dhe pragmatika, Tiranë: Ribotim, Albas

Eco, U. (2006). Të thuash gati të njëjtën gjë. Përvoja përkthimi. Tiranë: Dituria.

Dibra, K. \& Varfi, N (1999) Gjuhësi teksti. Tiranë: Botimet e Librit Universitar.

Fuga, A. (2008). Brirët e dhisë. Tiranë: Ora. 
